\title{
Self-efficacy: Toward a Unifying Theory of Behavioral Change
}

\author{
Albert Bandura \\ Stanford University
}

\begin{abstract}
The present article presents an integrative theoretical framework to explain and to predict psychological changes achieved by different modes of treatment. This theory states that psychological procedures, whatever their form, alter the level and strength of self-efficacy. It is hypothesized that expectations of personal efficacy determine whether coping behavior will be initiated, how much effort will be expended, and how long it will be sustained in the face of obstacles and aversive experiences. Persistence in activities that are subjectively threatening but in fact relatively safe produces, through experiences of mastery, further enhancement of self-efficacy and corresponding reductions in defensive behavior. In the proposed model, expectations of personal efficacy are derived from four principal sources of information: performance accomplishments, vicarious experience, verbal persuasion, and physiological states. The more dependable the experiential sources, the greater are the changes in perceived selfefficacy. A number of factors are identified as influencing the cognitive processing of efficacy information arising from enactive, vicarious, exhortative, and emotive sources. The differential power of diverse therapeutic procedures is analyzed in terms of the postulated cognitive mechanism of operation. Findings are reported from microanalyses of enactive, vicarious, and emotive modes of treatment that support the hypothesized relationship between perceived self-efficacy and behavioral changes. Possible directions for further research are discussed.
\end{abstract}

Current developments in the field of behavioral change reflect two major divergent trends. The difference is especially evident in the treatment of dysfunctional inhibitions and defensive behavior. On the one hand, the mechanisms by which human behavior is acquired and regulated are increasingly formulated in terms of cognitive processes. On the other hand, it is performance-based procedures that are proving to be most powerful for effecting psychological changes. As a consequence, successful performance is replacing symbolically based experiences as the principle vehicle of change.

The present article presents the view that changes achieved by different methods derive from a common cognitive mechanism. The

The research by the author reported in this article was supported by Research Grant M-5162 from the National Institutes of Health, United States Public Health Service.

Requests for reprints should be sent to Albert Bandura, Department of Psychology, Stanford University, Stanford, California 94305. apparent divergence of theory and practice can be reconciled by postulating that cognitive processes mediate change but that cognitive events are induced and altered most readily by experience of mastery arising from effective performance. The distinction between process and means is underscored, because it is often assumed that a cognitive mode of operation requires a symbolic means of induction. Psychological changes can be produced through other means than performance accomplishments. Therefore, the explanatory mechanism developed in this article is designed to account for changes in behavior resulting from diverse modes of treatment.

\section{Cognitive Locus of Operation}

Psychological treatments based on learning principles were originally conceptualized to operate through peripheral mechanisms. New behavior was presumably shaped automatically by its effects. Contingency learning through paired stimulation was construed in 
connectionist terms as a process in which responses were linked directly to stimuli. Altering the rate of preexisting behavior by reinforcement was portrayed as a process wherein responses were regulated by their immediate consequences without requiring any conscious involvement of the responders.

Growing evidence from several lines of research altered theoretical perspectives on how behavior is acquired and regulated. Theoretical formulations emphasizing peripheral mechanisms began to give way to cognitively oriented theories that explained behavior in terms of central processing of direct, vicarious, and symbolic sources of information. Detailed analysis of the empirical and conceptual issues (see Bandura, 1977) falls beyond the scope of the present article. To summarize briefly, however, it has now been amply documented that cognitive processes play a prominent role in the acquisition and retention of new behavior patterns. Transitory experiences leave lasting effects by being coded and retained in symbols for memory representation. Because acquisition of response information is a major aspect of learning, much human behavior is developed through modeling. From observing others, one forms a conception of how new behavior patterns are performed, and on later occasions the symbolic construction serves as a guide for action (Bandura, 1971). The initial approximations of response patterns learned observationally are further refined through self-corrective adjustments based on informative feedback from performance.

Learning from response consequences is also conceived of largely as a cognitive process. Consequences serve as an unarticulated way of informing performers what they must do to gain beneficial outcomes and to avoid punishing ones. By observing the differential effects of their own actions, individuals discern which responses are appropriate in which settings and behave accordingly (Dulany, 1968). Viewed from the cognitive framework, learning from differential outcomes becomes a special case of observational learning. In this mode of conveying response information, the conception of the appropriate behavior is gradually con- structed from observing the effects of one's actions rather than from the examples provided by others.

Changes in behavior produced by stimuli that either signify events to come or indicate probable response consequences also have been shown to rely heavily on cognitive representations of contingencies. People are not much affected by paired stimulation unless they recognize that the events are correlated (Dawson \& Furedy, 1976; Grings, 1973). Stimuli influence the likelihood of a behavior's being performed by virtue of their predictive function, not because the stimuli are automatically connected to responses by their having occurred together. Reinterpretation of antecedent determinants as predictive cues, rather than as controlling stimuli, has shifted the locus of the regulation of behavior from the stimulus to the individual.

The issue of the locus at which behavioral determinants operate applies to reinforcement influences as well as to antecedent environmental stimuli. Contrary to the common view that behavior is controlled by its immediate consequences, behavior is related to its outcomes at the level of aggregate consequences rather than momentary effects (Baum, 1973). People process and synthesize feedback information from sequences of events over long intervals about the situational circumstances and the patterns and rates of actions that are necessary to produce given outcomes. Since consequences affect behavior through the influence of thought, beliefs about schedules of reinforcement can exert greater influence on behavior than the reinforcement itself (Baron, Kaufman, \& Stauber, 1969; Kaufman, Baron, \& Kopp, 1966). Incidence of behavior that has been positively reinforced does not increase if individuals believe, based on other information, that the same actions will not be rewarded on future occasions (Estes, 1972); and the same consequences can increase, reduce, or have no effect on incidence of behavior depending on whether individuals are led to believe that the consequences signify correct responses, incorrect responses, or occur noncontingently (Dulany, 1968).

The discussion thus far has examined the 
role of cognition in the acquisition and regulation of behavior. Motivation, which is primarily concerned with activation and persistence of behavior, is also partly rooted in cognitive activities. The capacity to represent future consequences in thought provides one cognitively based source of motivation. Through cognitive representation of future outcomes individuals can generate current motivators of behavior. Seen from this perspective, reinforcement operations affect behavior largely by creating expectations that behaving in a certain way will produce anticipated benefits or avert future difficulties (Bolles, 1972b). In the enhancement of previously learned behavior, reinforcement is conceived of mainly as a motivational device rather than as an automatic response strengthener.

A second cognitively based source of motivation operates through the intervening influences of goal setting and self-evaluative reactions (Bandura, 1976b, 1977). Selfmotivation involves standards against which to evaluate performance. By making selfrewarding reactions conditional on attaining a certain level of behavior, individuals create self-inducements to persist in their efforts until their performances match self-prescribed standards. Perceived negative discrepancies between performance and standards create dissatisfactions that motivate corrective changes in behavior. Both the anticipated satisfactions of desired accomplishments and the negative appraisals of insufficient performance thus provide incentives for action. Having accomplished a given level of performance, individuals often are no longer satisfied with it and make further self-reward contingent on higher attainments.

The reconceptualization of human learning and motivation in terms of cognitive processes has major implications for the mechanisms through which therapeutic procedures alter behavioral functioning. Although the advances in cognitive psychology are a subject of increasing interest in speculations about behavioral change processes, few new theories of psychotherapy have been proposed that might prove useful in stimulating research on explanatory mechanisms

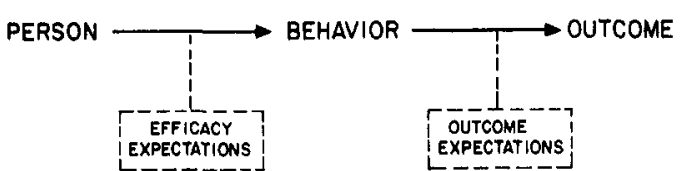

Figure 1. Diagrammatic representation of the difference between efficacy expectations and outcome expectations.

and in integrating the results accompanying diverse modes of treatment. The present article outlines a theoretical framework, in which the concept of self-efficacy is assigned a central role, for analyzing changes achieved in fearful and avoidant behavior. The explanatory value of this conceptual system is then evaluated by its ability to predict behavioral changes produced through different methods of treatment.

\section{Efficacy Expectations as a Mechanism of Operation}

The present theory is based on the principal asssumption that psychological procedures, whatever their form, serve as means of creating and strengthening expectations of personal efficacy. Within this analysis, efficacy expectations are distinguished from response-outcome expectancies. The difference is presented schematically in Figure 1.

An outcome expectancy is defined as a person's estimate that a given behavior will lead to certain outcomes. An efficacy expectation is the conviction that one can successfully execute the behavior required to produce the outcomes. Outcome and efficacy expectations are differentiated, because individuals can believe that a particular course of action will produce certain outcomes, but if they entertain serious doubts about whether they can perform the necessary activities such information does not influence their behavior.

In this conceptual system, expectations of personal mastery affect both initiation and persistence of coping behavior. The strength of people's convictions in their own effectiveness is likely to affect whether they will even try to cope with given situations. At this initial level, perceived self-efficacy influences 
choice of behavioral settings. People fear and tend to avoid threatening situations they believe exceed their coping skills, whereas they get involved in activities and behave assuredly when they judge themselves capable of handling situations that would otherwise be intimidating.

Not only can perceived self-efficacy have directive influence on choice of activities and settings, but, through expectations of eventual success, it can affect coping efforts once they are initiated. Efficacy expectations determine how much effort people will expend and how long they will persist in the face of obstacles and aversive experiences. The stronger the perceived self-efficacy, the more active the efforts. Those who persist in subjectively threatening activities that are in fact relatively safe will gain corrective experiences that reinforce their sense of efficacy, thereby eventually eliminating their defensive behavior. Those who cease their coping efforts prematurely will retain their selfdebilitating expectations and fears for a long time.

The preceding analysis of how perceived self-efficacy influences performance is not meant to imply that expectation is the sole determinant of behavior. Expectation alone will not produce desired performance if the component capabilities are lacking. Moreover, there are many things that people can do with certainty of success that they do not perform because they have no incentives to do so. Given appropriate skills and adequate incentives, however, efficacy expectations are a major determinant of people's choice of activities, how much effort they will expend, and of how long they will sustain effort in dealing with stressful situations.

\section{Dimensions of Efficacy Expectations}

Empirical tests of the relationship between expectancy and performance of threatening activities have been hampered by inadequacy of the expectancy analysis. In most studies the measures of expectations are mainly concerned with people's hopes for favorable outcomes rather than with their sense of per- sonal mastery. Moreover, expectations are usually assessed globally only at a single point in a change process as though they represent a static, unidimensional factor. Participants in experiments of this type are simply asked to judge how much they expect to benefit from a given procedure. When asked to make such estimates, participants assume, more often than not, that the benefits will be produced by the external ministrations rather than gained through the development of self-efficacy. Such global measures reflect a mixture of, among other things, hope, wishful thinking, belief in the potency of the procedures, and faith in the therapist. It therefore comes as no surprise that outcome expectations of this type have little relation to magnitude of behavioral change (Davison \& Wilson, 1973, Lick \& Bootzin, 1975).

Efficacy expectations vary on several dimensions that have important performance implications. They differ in magnitude. Thus when tasks are ordered in level of difficulty, the efficacy expectations of different individuals may be limited to the simpler tasks, extend to moderately difficult ones, or include even the most taxing performances. Efficacy expectations also differ in generality. Some experiences create circumscribed mastery expectations. Others instill a more generalized sense of efficacy that extends well beyond the specific treatment situation. In addition, expectancies vary in strength. Weak expectations are easily extinguishable by disconfirming experiences, whereas individuals who possess strong expectations of mastery will persevere in their coping efforts despite disconfirming experiences.

An adequate expectancy analysis, therefore, requires detailed assessment of the magnitude, generality, and strength of efficacy expectations commensurate with the precision with which behavioral processes are measured. Both efficacy expectations and performance should be assessed at significant junctures in the change process to clarify their reciprocal effects on each other. Mastery expectations influence performance and are, in turn, altered by the cumulative effects of one's efforts. 


\section{Sources of Efficacy Expectations}

In this social learning analysis, expectations of personal efficacy are based on four major sources of information: performance accomplishments, vicarious experience, verbal persuasion, and physiological states. Figure 2 presents the diverse influence procedures commonly used to reduce defensive behavior and presents the principal source through which each treatment operates to create expectations of mastery. Any given method, depending on how it is applied, may of course draw to a lesser extent on one or more other sources of efficacy information. For example, as we shall see shortly, performancebased treatments not only promote behavioral accomplishments but also extinguish fear arousal, thus authenticating self-efficacy through enactive and arousal sources of information. Other methods, however, provide fewer ways of acquiring information about one's capability for coping with threatening situations. By postulating a common mechanism of operation, this analysis provides a conceptual framework within which to study behavioral changes achieved by different modes of treatment.

Performance accomplishments. This source of efficacy information is especially influential because it is based on personal mastery experiences. Successes raise mastery expectations; repeated failures lower them, particularly if the mishaps occur early in the course of events. After strong efficacy expectations are developed through repeated success, the negative impact of occasional failures is likely to be reduced. Indeed, occasional failures that are later overcome by determined effort can strengthen self-motivated persistence if one finds through experience that even the most difficult obstacles can be mastered by sustained effort. The effects of failure on personal efficacy therefore partly depend on the timing and the total pattern of experiences in which the failures occur.

Once established, enhanced self-efficacy tends to generalize to other situations in which performance was self-debilitated by preoccupation with personal inadequacies (Bandura, Adams, \& Beyer, in press; Bandura, Jeffery, \& Gajdos, 1975). As a result, improvements in behavioral functioning transfer not only to similar situations but to activities that are substantially different from those on which the treatment was focused. Thus, for example, increased self-efficacy gained through rapid mastery of a specific animal phobia can

\section{EFFICACY EXPECTATIONS}

SOURCE

MODE OF INDUCTION
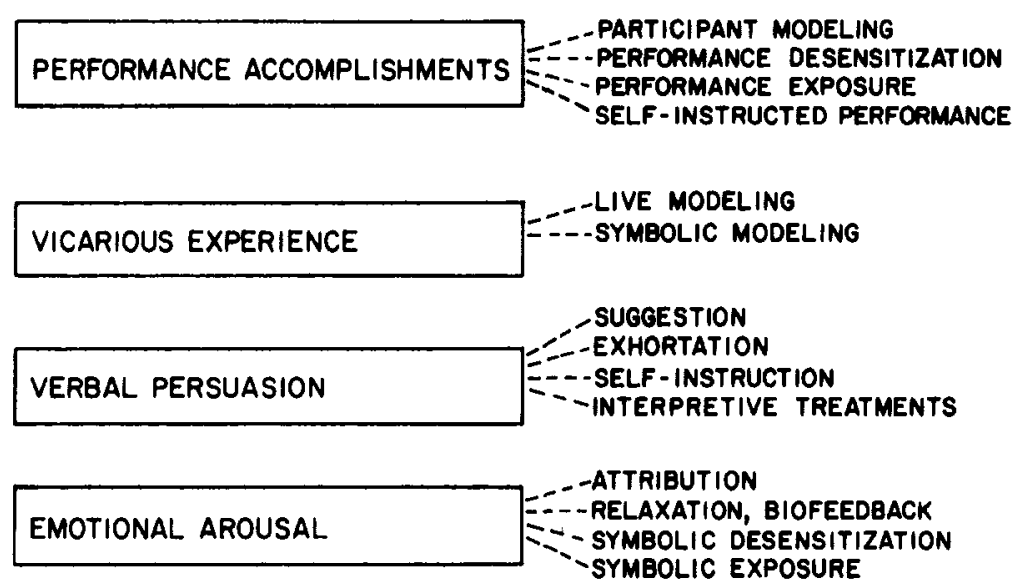

Figure 2. Major sources of efficacy information and the principal sources through which different modes of treatment operate. 
increase coping efforts in social situations as well as reduce fears of other animals. However, the generalization effects occur most predictably to the activities that are most similar to those in which self-efficacy was restored by treatment (Bandura, Blanchard, \& Ritter, 1969).

Methods of change that operate on the basis of performance accomplishments convey efficacy information in more ways than simply through the evidence of performance improvements. In the course of treatments employing modeling with guided performance, participants acquire a generalizable skill for dealing successfully with stressful situations, a skill that they use to overcome a variety of dysfunctional fears and inhibitions in their everyday life (Bandura et al., in press; Bandura et al., 1975). Having a serviceable coping skill at one's disposal undoubtedly contributes to one's sense of personal efficacy. Behavioral capabilities can also be enhanced through modeling alone (Bandura, 1971; Flanders, 1968). However, participant modeling provides additional opportunities for translating behavioral conceptions to appropriate actions and for making corrective refinements toward the perfection of skills.

Most of the treatment procedures developed in recent years to eliminate fearful and defensive behavior have been implemented either through performance or by symbolic procedures. Regardless of the methods involved, results of comparative studies attest to the superiority of performance-based treatments. In the desensitization approach devised by Wolpe (1974), clients receive graduated exposure to aversive events in conjunction with anxiety reducing activities, usually in the form of muscular relaxation. A number of experiments have been reported in which relaxation is paired with scenes in which phobics visualize themselves engaging in progressively more threatening activities or with enactment of the same hierarchy of activities with the actual threats. Findings based on different types of phobias consistently reveal that performance desensitization produces substantially greater behavioral change than does symbolic desensitization (LoPicollo, 1970;
Sherman, 1972; Strahley, 1966). Physiological measures yield similar results. Symbolic desensitization reduces autonomic responses to imagined but not to actual threats, whereas performance desensitization eliminates autonomic responses to both imagined and actual threats (Barlow, Leitenberg, Agras, \& Wincze, 1969). The substantial benefits of successful performance are typically achieved in less time than is required to extinguish arousal to symbolic representations of threats.

More recently, avoidance behavior has been treated by procedures involving massive exposure to aversive events. In this approach, intense anxiety is elicited by prolonged exposure to the most threatening situations and sustained at high levels, without relief, until emotional reactions are extinguished. Several investigators have compared the relative success of prolonged exposure to aversive situations in imagery and actual encounters with them in ameliorating chronic agoraphobias. Real encounters with threats produce results decidely superior to imagined exposure, which has weak, variable effects (Emmelkamp \& Wessels, 1975; Stern \& Marks, 1973; Watson, Mullett, \& Pillay, 1973). Prolonged encounters that ensure behavioral improvements are more effective than distributed brief encounters that are likely to end before successful performance of the activity is achieved (Rabavilas, Boulougouris, \& Stefanis, 1976).

The participant modeling approach to the elimination of defensive behavior utilizes successful performance as the primary vehicle of psychological change. People displaying intractable fears and inhibitions are not about to do what they dread. In implementing participant modeling, therapists therefore structure the environment so that clients can perform successfully despite their incapacities. This is achieved by enlisting a variety of response induction aids, including preliminary modeling of threatening activities, graduated tasks, enactment over graduated temporal intervals, joint performance with the therapist, protective aids to. reduce the likelihood of feared consequences, and variation in the severity of the threat itself (Bandura, Jeffery, \& Wright, 1974). As treatment progresses, 
the supplementary aids are withdrawn so that clients cope effectively unassisted. Selfdirected mastery experiences are then arranged to reinforce a sense of personal efficacy. Through this form of treatment incapacitated people rapidly lose their fears, they are able to engage in activities they formerly inhibited, and they display generalized reductions of fears toward threats beyond the specifically treated conditions (Bandura, 1976a).

Participant modeling has been compared with various symbolically based treatments. These studies corroborate the superiority of successful performance facilitated by modeling as compared to vicarious experience alone (Bandura et al., 1969; Blanchard, 1970b; Lewis, 1974; Ritter, 1969; Röper, Rachman, \& Marks, 1975), to symbolic desensitization (Bandura et al., 1969; Litvak, 1969), and to imaginal modeling in which clients visualize themselves or others coping successfully with threats (Thase \& Moss, 1976). When participant modeling is subsequently administered to those who benefit only partially from the symbolic procedures, avoidance behavior is thoroughly eliminated within a brief period.

The findings summarized above are consistent with self-efficacy theory, but they do not shed much light on the mechanism by which specific mastery experiences produce generalized and enduring changes in behavior. Verification of the operative mechanism requires experimental evidence that experienced mastery does in fact alter the level and strength of self-efficacy and that self-efficacy is, in turn, linked to behavior. We shall return later to research that addresses itself specifically to the linkages between treatment procedures, perceived self-efficacy, and behavior.

Vicarious experience. People do not rely on experienced mastery as the sole source of information concerning their level of selfefficacy. Many expectations are derived from vicarious experience. Seeing others perform threatening activities without adverse consequences can generate expectations in observers that they too will improve if they intensify and persist in their efforts. They persuade themselves that if others can do it, they should be able to achieve at least some improvement in performance (Bandura \& Barab, 1973). Vicarious experience, relying as it does on inferences from social comparison, is a less dependable source of information about one's capabilities than is direct evidence of personal accomplishments. Consequently, the efficacy expectations induced by modeling alone are likely to be weaker and more vulnerable to change.

A number of modeling variables that are apt to affect expectations of personal efficacy have been shown to enhance the disinhibiting influence of modeling procedures. Phobics benefit more from seeing models overcome their difficulties by determined effort than from observing facile performances by adept models (Kazdin, 1973; Meichenbaum, 1971). Showing the gains achieved by effortful coping behavior not only minimizes for observers the negative impact of temporary distress but demonstrates that even the most anxious can eventually succeed through perseverance. Similarity to the model in other characteristics, which increases the personal relevance of vicariously derived information, can likewise enhance the effectiveness of symbolic modeling (Kazdin, 1974b).

Modeled behavior with clear outcomes conveys more efficacy information than if the effects of the modeled actions remain ambiguous. In investigations of vicarious processes, observing one perform activities that meet with success does, indeed, produce greater behavioral improvements than witnessing the same performances modeled without any evident consequences (Kazdin, 1974c, 1975). Diversified modeling, in which the activities observers regard as hazardous are repeatedly shown to be safe by a variety of models, is superior to exposure to the same performances by a single model (Bandura \& Menlove, 1968; Kazdin, 1974a, 1975, 1976). If people of widely differing characteristics can succeed, then observers have a reasonable basis for increasing their own sense of self-efficacy.

The pattern of results reported above offers at least suggestive support for the view that exemplifications of success through sus- 
tained effort with substantiating comparative information can enhance observers' perceptions of their own performance capabilities. Research will be presented below that bears more directly on the proposition that modeling procedures alter avoidance behavior through the intervening influence of efficacy expectations.

Verbal persuasion. In attempts to influence human behavior, verbal persuasion is widely used because of its ease and ready availability. People are led, through suggestion, into believing they can cope successfully with what has overwhelmed them in the past. Efficacy expectations induced in this manner are also likely to be weaker than those arising from one's own accomplishments because they do not provide an authentic experiential base for them. In the face of distressing threats and a long history of failure in coping with them, whatever mastery expectations are induced by suggestion can be readily extinguished by disconfirming experiences.

Results of several lines of research attest to the limitation of procedures that attempt to instill outcome expectations in people simply by telling them what to expect. In laboratory studies, "placebo" conditions designed suggestively to raise expectations of improvement produce little change in refractory behavior (Lick \& Bootzin, 1975; Moore, 1965; Paul, 1966). Whether this is due to the low credibility of the suggestions or to the weakness of the induced expectations cannot be determined from these studies, because the expectations were not measured.

Numerous experiments have been conducted in which phobics receive desensitization treatment without any expectancy information or with suggestions that it is either highly efficacious or ineffective. The differential outcome expectations are verbally induced prior to, during, or immediately after treatment in the various studies. The findings generally show that desensitization reduces phobic behavior, but the outcome expectancy manipulations have either no effect or weak, inconsistent ones (Howlett \& Nawas, 1971; McGlynn \& Mapp, 1970; McGlynn, Mealiea, \& Nawas, 1969; McGlynn, Reynolds, \&
Linder, 1971). As in the "placebo" studies, it is difficult to make conclusive interpretations because the outcome expectations induced suggestively are not measured prior to the assessment of behavior changes, if at all. Simply informing participants that they will or will not benefit from treatment does not mean that they necessarily believe what they are told, especially when it contradicts their other personal experiences. Moreover, in the studies just cited the verbal influence is aimed mainly at raising outcome expectations rather than at enhancing self-efficacy. It is changes on the latter dimension that are most relevant to the theory under discussion.

Although social persuasion alone may have definite limitations as a means of creating an enduring sense of personal efficacy, it can contribute to the successes achieved through corrective performance. That is, people who are socially persuaded that they possess the capabilities to master difficult situations and are provided with provisional aids for effective action are likely to mobilize greater effort than those who receive only the performance aids. However, to raise by persuasion expectations of personal competence without arranging conditions to facilitate effective performance will most likely lead to failures that discredit the persuaders and further undermine the recipients' perceived self-efficacy. It is therefore the interactive, as well as the independent, effects of social persuasion on self-efficacy that merit experimental consideration.

Emotional arousal. Stressful and taxing situations generally elicit emotional arousal that, depending on the circumstances, might have informative value concerning personal competency. Therefore, emotional arousal is another constituent source of information that can affect perceived self-efficacy in coping with threatening situations. People rely partly on their state of physiological arousal in judging their anxiety and vulnerability to stress. Because high arousal usually debilitates performance, individuals are more likely to expect success when they are not beset by aversive arousal than if they are tense and viscerally agitated. Fear reactions gen- 
erate further fear of impending stressful situations through anticipatory self-arousal. By conjuring up fear-provoking thoughts about their ineptitude, individuals can rouse themselves to elevated levels of anxiety that far exceed the fear experienced during the actual threatening situation.

As will be recalled from the earlier discussion, desensitization and massive exposure treatments aimed at extinguishing anxiety arousal produce some reductions in avoidance behavior. Anxiety arousal to threats is likewise diminished by modeling, and is even more thoroughly eliminated by experienced mastery achieved through participant modeling (Bandura \& Barab, 1973; Bandura et al., 1969; Blanchard, 1970a). Modeling approaches have other advantages for enhancing self-efficacy and thereby removing dysfunctional fears. In addition to diminishing proneness to aversive arousal, such approaches also teach effective coping skills by demonstrating proficient ways of handling threatening situations. The latter contribution is especially important when fear arousal partly results from behavioral deficits. It is often the case that fears and deficits are interdependent. Avoidance of stressful activities impedes development of coping skills, and the resulting lack of competency provides a realistic basis for fear. Acquiring behavioral means for controlling potential threats attenuates or eliminates fear arousal (Averill, 1973; Notterman, Schoenfeld, \& Bersh, 1952; Szpiler \& Epstein, 1976). Behavioral control not only allows one to manage the aversive aspects of an environment. It also affects how the environment is likely to be perceived. Potentially stressful situations that can be controlled are construed as less threatening, and such cognitive appraisals further reduce anticipatory emotional arousal (Averill, 1973).

Diminishing emotional arousal can reduce avoidance behavior, but different theories posit different explanatory mechanisms for the observed effects. In the theory from which the emotive treatments are derived, emotional arousal is conceived of as a drive that activates avoidance behavior. This view stresses the energizing function of arousal and the reinforcing function of arousal reduction. Social learning theory, on the other hand, emphasizes the informative function of physiological arousal. Simply acknowledging that arousal is both informative and motivating by no means resolves the issue in dispute, because these are not necessarily two separate effects that somehow jointly produce behavior. Rather, the cognitive appraisal of arousal to a large extent determines the level and direction of motivational inducements to action. Certain cognitive appraisals of one's physiological state might be energizing, whereas other appraisals of the same state might not (Weiner, 1972). Moreover, many forms of physiological arousal are generated cognitively by arousing trains of thought. When motivation is conceptualized in terms of cognitive processes (Bandura, 1977; Weiner, 1972), the informational and motivational effects of arousal are treated as interdependent rather than as separate events. We shall return to this issue later when we consider the differential predictions made from social learning theory and from the dual-process theory of avoidance behavior concerning the behavioral effects of extinguishing anxiety arousal.

Researchers working within the attributional framework have attempted to modify avoidance behavior by directly manipulating the cognitive labeling of emotional arousal (Valins \& Nisbett, 1971). The presumption is that if phobics are led to believe that the things they have previously feared no longer affect them internally, the cognitive reevaluation alone will reduce avoidance behavior. In treatment analogues of this approach, phobics receive false physiological feedback suggesting that they are no longer emotionally upset by threatening events. Results of this procedure are essentially negative. Early claims that erroneous arousal feedback reduces avoidance behavior (Valins \& Ray, 1967) are disputed by methodologically superior studies showing that false feedback of physiological tranquility in the presence of threats has either no appreciable effect on subsequent fearful behavior (Gaupp, Stern, \& Galbraith, 1972; Howlett \& Nawas, 1971; Kent, Wilson, \& Nelson, 1972; Rosen, Rosen, \& Reid, 1972; Sushinsky \& Bootzin, 
1970), or produces minor changes under such limited conditions as to be of little practical consequence (Borkovec, 1973).

Misattribution of emotional arousal is another variant of the attributional approach to modification of fearful behavior. The strategy here is to lead fearful people into believing that their emotional arousal is caused by a nonemotional source. To the extent that they no longer label their agitated state as anxiety, they will behave more boldly. It may be possible to reduce mild fears by this means (Ross, Rodin, \& Zimbardo, 1969), but the highly anxious are not easily led into misattributing their anxiety to irrelevant sources (Nisbett \& Schachter, 1966). When evaluated systematically, misattribution treatments do not produce significant changes in chronic anxiety conditions (Singerman, Borkovec, \& Baron, 1976), and some of the benefits reported with other dysfunctions cannot be replicated (Bootzin, Herman, \& Nicasşio, 1976; Kellogg \& Baron, 1975 ). There is also some suggestive evidence that in laboratory studies the attenuation of fear may be due more to the veridicality of arousal information than to misattribution of fear arousal to an innocuous source (CalvertBoyanowsky \& Leventhal, 1975).

Any reduction in fear resulting from deceptive feedback is apt to be short-lived because illusory assurances are not an especially reliable way of creating durable selfexpectations. However, more veritable experiences that reduce the level of emotional arousal can set in motion a reciprocal process of change. In the social learning view, potential threats activate fear largely through cognitive self-arousal (Bandura, 1969, 1977). Perceived self-competence can therefore affect susceptibility to self-arousal. Individuals who come to believe that they are less vulnerable than they previously assumed are less prone to generate frightening thoughts in threatening situations. Those whose fears are relatively weak may reduce their selfdoubts and debilitating self-arousal to the point where they perform successfully. Performance successes, in turn, strengthen selfefficacy. Such changes can, of course, be reliably achieved without resort to ruses.
Moreover, mislabeling arousal or attributing it to erroneous sources is unlikely to be of much help to the highly anxious. Severe acrophobics, for example, may be temporarily misled into believing that they no longer fear high elevations, but they will reexperience unnerving internal feedback when confronted with dreaded heights. It should also be noted that in attributional explanations of the success of behavioral treatments the heavy emphasis on physiological arousal derives more from speculations about the nature of emotion (Schachter, 1964) than from evidence that arousal is a major determinant of defensive behavior.

\section{Cognitive Processing of Efficacy Information}

The discussion thus far has centered primarily on the many sources of informationenactive, vicarious, exhortative, and emotive - that people use to judge their level of self-efficacy. At this point a distinction must be drawn between information contained in environmental events and information as processed and transformed by the individual. The impact of information on efficacy expectations will depend on how it is cognitively appraised. A number of contextual factors, including the social, situational, and temporal circumstances under which events occur, enter into such appraisals. For this reason, even success experiences do not necessarily create strong generalized expectations of personal efficacy. Expectations that have served selfprotective functions for years are not quickly discarded. When experience contradicts firmly established expectations of self-efficacy, they may undergo little change if the conditions of performance are such as to lead one to discount the import of the experience.

The corrective value of information derived from successful performance can be attenuated in several ways. The first involves discrimination processes. The consequences individuals anticipate were they to perform feared activities differ in circumstances which vary in safeguards. As a result, they may behave boldly in situations signifying safety, but retain unchanged their self-doubts under less secure conditions. Such mitigative discriminations can extend to the treatments 
themselves, as well as to the situational circumstances in which behavioral attainments occur. This is especially true of treatments relying solely on symbolic and vicarious experience. Achieving reductions in fear to threats presented symbolically is unlikely to enhance perceived self-efficacy to any great extent in people who believe that success in imagery does not portend accomplishments in reality. Information conveyed by facilely modeled performances might likewise be minimized by anxious observers on the grounds that the models possess special expertise enabling them to prevent injurious consequences that might otherwise befall the unskilled. Because such discriminations, even though objectively mistaken, impede change in self-efficacy, observers will be reluctant to attempt feared activities and will be easily dissuaded by negative experience.

Cognitive appraisals of the causes of one's behavior, which have been examined extensively in investigations of self-attributional processes (Bem, 1972), can similarly delimit gains in self-efficacy from behavioral attainments. It was previously shown that attributions of affect and actions to illusory competence have little, if any, effect on refractory behavior. This does not, of course, mean that causal appraisals are of limited importance in the process of behavior change. Quite the contrary, performance attainment is a prominent source of efficacy information, but it is by no means unambiguous. As already mentioned briefly, people can gain competence through authentic means but, because of faulty appraisals of the circumstances under which they improve, will credit their achievements to external factors rather than to their own capabilities. Here the problem is one of inaccurate ascription of personal competency to situational factors. Successes are more likely to enhance selfefficacy if performances are perceived as resulting from skill than from fortuitous or special external aids. Conversely, failures would be expected to produce greater reductions in self-efficacy when attributed to ability rather than to unusual situational circumstances. The more extensive the situational aids for performance, the greater are the chances that behavior will be ascribed to external factors (Bem, 1972; Weiner, 1972).

Even under conditions of perceived selfdetermination of outcomes, the impact of performance attainments on self-efficacy will vary depending on whether one's accomplishments are ascribed mainly to ability or to effort. Success with minimal effort fosters ability ascriptions that reinforce a strong sense of self-efficacy. By contrast, analogous successes achieved through high expenditure of effort connote a lesser ability and are thus likely to have a weaker effect on perceived self-efficacy. Cognitive appraisals of the difficulty level of the tasks will further affect the impact of performance accomplishments on perceived self-efficacy. To succeed at easy tasks provides no new information for altering one's sense of self-efficacy, whereas mastery of challenging tasks conveys salient evidence of enhanced competence. The rate and pattern of attainments furnish additional information for judging personal efficacy. Thus, people who experience setbacks but detect relative progress will raise their perceived efficacy more than those who succeed but see their performances leveling off compared to their prior rate of improvement.

Extrapolations from theories about attribution and self-perception to the field of behavioral change often imply that people must labor unaided or under inconspicuously arranged influences if they are to convince themselves of their personal competence (Kopel \& Arkowitz, 1975). Such prescriptions are open to question on both conceptual and empirical grounds. Cognitive misappraisals that attenuate the impact of disconfirming experiences can be minimized without sacrificing the substantial benefits of powerful induction procedures. This is achieved by providing opportunities for selfdirected accomplishments after the desired behavior has been established. Any lingering doubts people might have, either about their capabilities or about probable response consequences under unprotected conditions, are dispelled easily in this manner (Bandura et al., 1975). The more varied the circumstances in which threats are mastered in- 
dependently, the more likely are success experiences to authenticate personal efficacy and to impede formation of discriminations that insulate self-perceptions from disconfirming evidence.

Results of recent studies support the thesis that generalized, lasting changes in self-efficacy and behavior can best be achieved by participant methods using powerful induction procedures initially to develop capabilities, then removing external aids to verify personal efficacy, then finally using self-directed mastery to strengthen and generalize expectations of personal efficacy (Bandura et al., 1975). Independent performance can enhance efficacy expectations in several ways: (a) It creates additional exposure to former threats, which provides participants with further evidence that they are no longer aversively aroused by what they previously feared. Reduced emotional arousal confirms increased coping capabilities. (b) Self-directed mastery provides opportunities to perfect coping skills, which lessen personal vulnerability to stress. (c) Independent performance, if well executed, produces success experiences, which further reinforce expectations of self-competency.

Extensive self-directed performance of formerly threatening activities under progressively challenging conditions at a time when treatments are usually terminated could also serve to reduce susceptibility to relearning of defensive patterns of behavior. A few negative encounters among many successful experiences that have instilled a strong sense of self-efficacy will, at most, establish discriminative avoidance of realistic threats, an effect that has adaptive value. In contrast, if people have limited contact with previously feared objects after treatment, whatever expectations of self-efficacy were instated would be weaker and more vulnerable to change. Consequently, a few unfavorable experiences are likely to reestablish defensive behavior that generalizes inappropriately.

We have already examined how cognitive processing of information conveyed by modeling might influence the extent to which vicarious experience effects changes in selfefficacy. Among the especially informative elements are the models' characteristics (e.g., adeptness, perseverance, age, expertness), the similarity between models and observers, the difficulty of the performance tasks, the situational arrangements under which the modeled achievements occur, and the diversity of modeled attainments.

Just as the value of efficacy information generated enactively and vicariously depends on cognitive appraisal, so does the information arising from exhortative and emotive sources. The impact of verbal persuasion on self-efficacy may vary substantially depending on the perceived credibility of the persuaders, their prestige, trustworthiness, expertise, and assuredness. The more believable the source of the information, the more likely are efficacy expectations to change. The influence of credibility on attitudinal change has, of course, received intensive study. But its effects on perceived self-efficacy remain to be investigated.

People judge their physiological arousal largely on the basis of their appraisal of the instigating conditions. Thus, visceral arousal occurring in situations perceived to be threatening is interpreted as fear, arousal in thwarting situations is experienced as anger, and that resulting from irretrievable loss of valued objects as sorrow (Hunt, Cole, \& Reis, 1958). Even the same source of physiological arousal may be interpreted differently in ambiguous situations depending on the emotional reactions of others in the same setting (Mandler, 1975; Schachter \& Singer, 1962).

When tasks are performed in ambiguous or complex situations in which there is a variety of evocative stimuli, the informational value of the resultant arousal will depend on the meaning imposed upon it. People who perceive their arousal as stemming from personal inadequacies are more likely to lower their efficacy expectations than those who attribute their arousal to certain situational factors. Given a proneness to ascribe arousal to personal deficiencies, the heightened attention to internal events can result in reciprocally escalating arousal. Indeed, as Sarason (1976) has amply documented, individuals who are especially susceptible to anxiety arousal 
readily become self-preoccupied with their perceived inadequacies in the face of difficulties rather than with the task at hand.

\section{Differing Perspectives on Self-efficacy}

The phenomena encompassed by the construct of self-efficacy have been the subject of interest in other theories of human behavior. The theoretical perspectives differ, however, in how they view the nature and origins of personal efficacy and the intervening processes by which perceived self-efficacy affects behavior. In seeking a motivational explanation of exploratory and manipulative behavior, White (1959) postulated an "effectance motive," which is conceptualized as an intrinsic drive for transactions with the environment. Unlike instigators arising from tissue deficits, effectance motivation is believed to be aroused by novel stimulation and is sustained when the resultant inquisitive and exploratory actions produce further elements of novelty in the stimulus field. The effectance motive presumably develops through cumulative acquisition of knowledge and skills in dealing with the environment. However, the process by which an effectance motive emerges from effective transactions with the environment is not spelled out in White's theory. Nor is the existence of the motive easy to verify, because effectance motivation is inferred from the exploratory behavior it supposedly causes. Without an independent measure of motive strength one cannot tell whether people explore and manipulate things because of a competence motive to do so, or for any number of other reasons. Athough the theory of effectance motivation has not been formulated in sufficient detail to permit extensive theoretical comparisons, there are several issues on which the social learning and effectance theories clearly differ.

In the social learning analysis, choice behavior and effort expenditure are governed in part by percepts of self-efficacy rather than by a drive condition. Because efficacy expectations are defined and measured independently of performance, they provide an explicit basis for predicting the occurrence, generality, and persistence of coping be- havior, whereas an omnibus motive does not. People will approach, explore, and try to deal with situations within their selfperceived capabilities, but they will avoid transactions with stressful aspects of their environment they perceive as exceeding their ability.

The alternative views also differ on the origins of efficacy. Within the framework of effectance theory, the effectance drive develops gradually through prolonged transactions with one's surroundings. This theory thus focuses almost exclusively on the effects produced by one's own actions. In the social learning theory, self-efficacy is conceptualized as arising from diverse sources of information conveyed by direct and mediated experience. These differences in theoretical approach have significant implications for how one goes about studying the role of perceived self-efficacy in motivational and behavioral processes. Expectations of personal efficacy do not operate as dispositional determinants independently of contextual factors. Some situations require greater skill and more arduous performances and carry higher risk of negative consequences than do others. Expectations will vary accordingly. Thus, for example, the level and strength of perceived self-efficacy in public speaking will differ depending on the subject matter, the format of the presentation, and the types of audiences that will be addressed. The social learning approach is therefore based on a microanalysis of perceived coping capabilities rather than on global personality traits or motives of effectance. From this perspective, it is no more informative to speak of selfefficacy in general terms than to speak of nonspecific approach behavior. To elucidate how perceived self-efficacy affects behavior requires a microanalysis of both factors.

Discrepancies between efficacy expectations and performance are most likely to arise under conditions in which situational and task factors are ambiguous. When performance requirements are ill-defined, people who underestimate the situational demands will display positive discrepancies between self-efficacy and performance attainments; those who overestimate the demands will 
exhibit negative discrepancies. Therefore, in testing predictions from the conceptual scheme presented here it is important that subjects understand what kind of behavior will be required and the circumstances in which they will be asked to perform them. Moreover, performances and the corresponding efficacy expectations should be analyzed into separate activities, and preferably ordered by level of difficulty. In this type of microanalysis both the efficacy expectations and the corresponding behaviors are measured in terms of explicit types of performances rather than on the basis of global indices.

The social learning determinants of selfefficacy can be varied systematically and their effects measured. Hence, propositions concerning the origins of self-efficacy are verifiable with some precision. A slowly developing motive, however, does not easily lend itself to being tested experimentally. Another dimension on which the alternative theories might be judged is their power to produce the phenomena they purport to explain. As we shall see later, there are more diverse, expeditious, and powerful ways of creating self-efficacy than by relying solely on novel stimulation arising from exploratory actions.

With the ascendency of cognitive views of behavior, the concept of expectancy is assuming an increasingly prominent place in contemporary psychological thought (Bolles, 1972b; Heneman, \& Schwab, 1972; Irwin, 1971). However, virtually all of the theorizing and experimentation has focused on action-outcome expectations. The ideas advanced in some of the theories nevertheless bear some likeness to the notion of selfefficacy. According to the theory of personality proposed by Rotter (1966), behavior varies as a function of generalized expectancies that outcomes are determined by one's actions or by external forces beyond one's control. Such expectations about the instrumentality of behavior are considered to be largely a product of one's history of reinforcement. Much of the research within this tradition is concerned with the behavioral correlates of individual differences in the tend- ency to perceive events as being either personally or externally determined.

The notion of locus of control is often treated in the literature as analogous to selfefficacy. However, Rotter's (1966) conceptual scheme is primarily concerned with causal beliefs about action-outcome contingencies rather than with personal efficacy. Perceived self-efficacy and beliefs about the locus of causality must be distinguished, because convictions that outcomes are determined by one's own actions can have any number of effects on self-efficacy and behavior. People who regard outcomes as personally determined but who lack the requisite skills would experience low self-efficacy and view activities with a sense of futility. Thus, for example, a child who fails to grasp arithmetic concepts and expects course grades to be dependent entirely on skill in the subject matter has every reason to be demoralized. While causal beliefs and self-efficacy refer to different phenomena, as we have already noted, causal ascriptions of behavior to skill or to chance can mediate the effects of performance attainments on self-efficacy.

The theoretical framework presented in the present article is generalizable beyond the psychotherapy domain to other psychological phenomena involving behavioral choices and regulation of effort in activities that can have adverse effects. For example, the theory of learned helplessness advanced by Maier and Seligman (1976) assumes that as a result of being subjected to uncontrollable aversive events, organisms acquire expectancies that actions do not affect outcomes. Because they come to expect future responding to be futile, they no longer initiate behavior in situations where outcomes are in fact controllable by responses. Although this theory posits an expectancy mechanism of operation, it focuses exclusively on response-outcome expectancies.

Theorizing and experimentation on learned helplessness might well consider the conceptual distinction between efficacy and outcome expectations. People can give up trying because they lack a sense of efficacy in achieving the required behavior, or they may be assured of their capabilities but give up 
trying because they expect their behavior to have no effect on an unresponsive environment or to be consistently punished. These two separable expectancy sources of futility have quite different antecedents and remedial implications. To alter efficacy-based futility requires development of competencies and expectations of personal effectiveness. By contrast, to change outcome-based futility necessitates changes in prevailing environmental contingencies that restore the instrumental value of the competencies that people already possess.

\section{Microanalysis of Self-efficacy and Behavioral Change}

To test derivations from the social learning analysis of the process of change, an experiment was conducted wherein severe phobics received treatments designed to create differential levels of efficacy expectations, and then the relationship between selfefficacy and behavioral change was analyzed in detail (Bandura et al., in press). The experiment proceeded as follows. Adult snake phobics, whose phobias affected their lives adversely, were administered for equivalent periods either participant modeling, modeling alone, or no treatment. In participant modeling, which operates through direct mastery experiences, subjects were assisted, by whatever induction aids were needed, to engage in progressively more threatening interactions with a boa constrictor. After completing all the therapeutic tasks, which included holding the snake, placing open hands in front of its head as it moved about the room, holding the snake in front of their faces, and allowing it to crawl freely in their laps, the subjects engaged in a brief period of self-directed mastery. In the present experiment, the modeling aid was used only briefly if needed to help initiate performance in order to minimize overlap of this element in the two modes of treatment.

Subjects receiving the modeling treatment merely observed the therapist perform the same activities for an equivalent period. These subjects did not engage in any behavior themselves, and consequently they had no performance sources of information for their efficacy expectations. Enactive and vicarious procedures were selected for study to assess the predictive value of self-efficacy created by quite different modes of treatment.

The level, strength, and generality of the subjects' efficacy expectations were measured at critical junctures in the change process. Subjects privately designated, on a list of 18 performance tasks ranked in order of increasing threat, those tasks they considered themselves capable of executing. They then rated the strength of their expectations for each of these tasks on a 100-point probability scale ranging, in 10-unit intervals, from great uncertainty, through intermediate values of certainty, to complete certainty. They rated their efficacy expectations for coping with snakes of the same variety used in treatment as well as dissimilar snakes to measure the generality of their efficacy expectations. These measures were obtained prior to treatment, following treatment but before the behavioral posttest, and after completing the posttest. Approach behavior was assessed in the posttest by a series of performance tasks requiring increasingly more threatening interactions with a different type of boa constrictor from the one used in treatment and with a corn snake of markedly different appearance but equivalent threat value. Different phobic objects were used to provide a test of the generalized effects of changes in efficacy expectations along a dimension of similarity to the threat used in treatment.

Subjects assigned to the control condition participated in the assessment procedures without receiving any intervening treatment. Following completion of the posttest, the controls and those in the modeling condition who failed to achieve terminal performances received the participant modeling treatment.

Consistent with the social learning analysis of the sources of self-efficacy, experiences based on performance accomplishments produced higher, more generalized, and stronger efficacy expectations than did vicarious experience, which in turn exceeded those in the control condition. Figure 3 summarizes the level of efficacy expectations and performance as a function of treatment condi- 

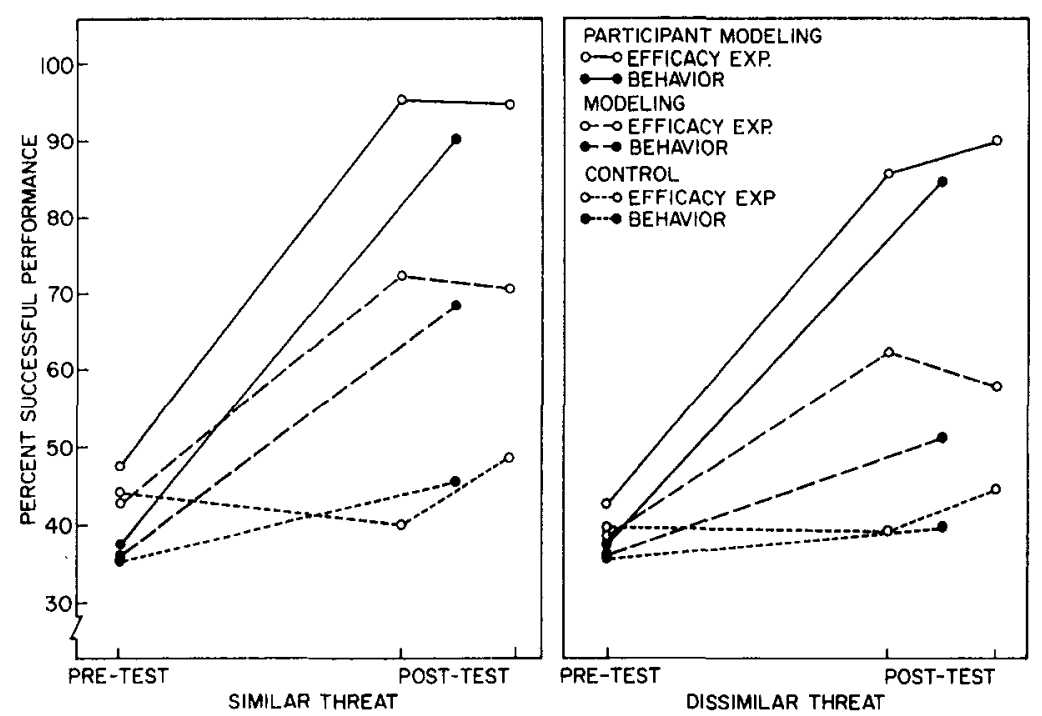

Figure 3. Level of efficacy expectations and approach behavior displayed by subjects toward threats after receiving vicarious or enactive treatments, or no treatment (Bandura et al., in press).

tions at different phases of the experiment. As shown in the figure, performance change corresponds closely to the magnitude of expectancy change. The greater the increments in self-perceived efficacy, the greater the changes in behavior. Similar relationships between level of self-efficacy and performance are obtained when the data are considered separately for the two snakes. In accordance with prediction, participant modeling produced the more generalized increases in efficacy expectations and the more generalized behavioral changes.

Although the enactive and vicarious treatments differed in their power to enhance self-efficacy, the efficacy expectations were equally predictive of subsequent performance irrespective of how they were instated. The higher the level of perceived self-efficacy at the completion of treatment the higher was the level of approach behavior for efficacy expectations instated enactively $(r=.83)$ and vicariously $(r=.84)$. It might be noted here that all subjects had at their disposal the component responses for producing the interactive patterns of behavior, and they all had some incentive to overcome their phobic behavior. Under conditions in which people differ substantially in component capabilities and motivation, skill and incentive factors will also contribute to variance in performance.

Correlation coefficients based on aggregate measures do not fully reveal the degree of correspondence between self-efficacy and performance on the specific behavioral tasks from which the aggregate scores are obtained. A subject can display an equivalent number of efficacy expectations and successful performances, but they might not correspond entirely to the same tasks. The most precise index of the relationship is provided by a microanalysis of the congruence between selfefficacy and performance at the level of individual tasks. This measure was obtained by recording whether or not subjects considered themselves capable of performing each of the various tasks at the end of treatment and by computing the percentage of accurate correspondence between efficacy judgment and actual performance. Self-efficacy was a uniformly accurate predictor of performance on tasks varying in difficulty with different threats regardless of whether the changes in self-efficacy were produced through performance accomplishments ( $89 \%$ congruence) or by vicarious experience alone (86\% congruence). The degree of congruence between perceived self-efficacy and subsequent behavior is equally high for enactive ( $82 \%)$ and 
vicarious $(79 \%)$ treatments when the microanalysis is conducted only on the subset of tasks that subjects had never performed in the pretest assessment.

In the preceding analysis efficacy expectations were considered without regard to strength. A weak sense of self-efficacy thus received the same weight as one reflecting complete certitude. However, the intensity and persistence of effort, and hence level of performance, should be higher with strong than with weak self-efficacy. The likelihood that a task will be performed as a function of the strength of the corresponding efficacy expectation therefore provides a further refinement in the analysis of the relationship between self-efficacy and performance. The probability of successful performance of any given task as a function of strength of efficacy expectations is plotted in Figure 4. Because the control subjects performed few responses and had correspondingly restricted efficacy expectations, their data were plotted after they had received the participant modeling treatment. In all conditions, the stronger the efficacy expectations, the higher was the likelihood that a particular task would be successfully completed. The positive relationship between strength of self-efficacy and probability of successful performance is virtually identical for the similar and the dissimilar threats.

In brief, the theory systematizes a variety of findings. As the preceding results show, it predicts accurately the magnitude and generality of behavioral change for efficacy expectations induced enactively and vicariously. Moreover, it orders variations in level of behavioral change occurring within the same treatment condition. Subjects who received participant modeling, either as the primary or as the supplementary treatment, successfully performed all of the behaviors in treatment that were later assessed in the posttest toward different threats. Although all had previously achieved maximal performances, not all expressed maximal efficacy expectations. One can therefore compare the error rates of predictions made from maximal past performance and from maximal efficacy expectations. It would be predicted from the proposed theory that among these successful performers, those who acquire maximal efficacy expectations should attain terminal performances, whereas those holding lower expectations should not. If one predicts that those who performed maximally in treatment will likewise achieve terminal performances when assessed with similar tasks, the error rate is relatively low for the similar threat $(28 \%)$ but high for the dissimilar threat $(52 \%)$. If, on the other hand, one predicts that those who express maximal expectations will perform maximally, the error rate is comparably low for both the similar $(21 \%)$ and the dissimilar $(24 \%)$ threats. The predictive superiority of efficacy expectations over past performance is significant for total

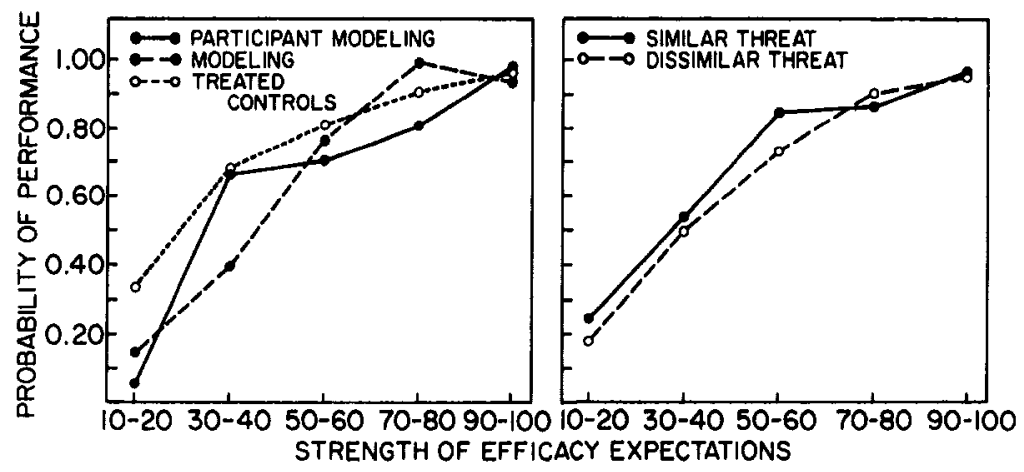

Figure 4. Probability of successful performance of ary given task as a function of strength of self-efficacy. The figure on the left shows the relationship for vicarious and enactive treatments; the figure on the right shows the relationship between strength of self-efficacy and successful approach responses toward similar and dissimilar threats combined across treatments (Bandura et al., in press). 
approach behavior and for approach behavior toward the dissimilar threat. These differential findings indicate that experienced mastery altered subjects' sense of personal efficacy rather than merely providing behavioral cues for judgments of self-efficacy.

The theory also accounts for variations in behavioral change produced by modeling alone. To equate for duration of treatment, subjects in the modeling condition were yoked to matched counterparts in participant modeling, who received treatment until they performed all the therapeutic tasks. The subjects in the participant modeling condition varied in the time they required to complete treatment, so some of the subjects in the modeling conditions had only brief exposure to successful performances, whereas others had the benefit of observing feared activities modeled repeatedly without any untoward consequences. The findings are consistent with hypothesized increases in selfefficacy as a function of repeated observation of successful modeling. Brief exposure produced limited increases in the level $(9 \%)$ and strength $(5 \%)$ of efficacy expectations and correspondingly little behavior change $(10 \%)$. In contrast, repeated observation of successful performances increased by a substantial amount the level $(44 \%)$ and strength $(38 \%)$ of self-efficacy which, in turn, was accompanied by similarly large increments in performance $(35 \%)$.

\section{Comparison of Self-efficacy and Dual-Process Theory}

As a further test of the generality of the theory under discussion, a microanalysis was conducted of efficacy expectations instated by desensitization procedures, which are aimed at reducing emotional arousal. Social learning theory and the dual-process theory of anxiety, on which the desensitization approach is based, posit different explanatory mechanisms for the changes accompanying this mode of treatment. The alternative views therefore give rise to differential predictions that can be readily tested.

The standard desensitization approach is based on the assumption that anxiety activates defensive behavior (Wolpe, 1974). According to this view, association of neutral events with aversive stimulation creates an anxiety drive that motivates defensive behavior; the defensive behavior, in turn, is reinforced by reducing the anxiety aroused by conditioned aversive stimuli. Hence, to eliminate defensive responding, it is considered necessary to eradicate its underlying anxiety. Treatment strategies are therefore keyed to reduction of emotional arousal. Aversive stimuli are presented at graduated levels in conjunction with relaxation until anxiety reactions to the threats are eliminated.

Although desensitization produces behavioral changes, there is little evidence to support the original rationale that defensive behavior is diminished because anxiety is eliminated either by reciprocal physiological inhibition or by associative recoupling of threatening stimuli to relaxation. Desensitization does not require graduated exposure, and anxiety-reducing activities are at most facilitory, not necessary, conditions for eliminating defensive behavior (Bandura, 1969; Wilson \& Davison, 1971).

The principal assumption that defensive behavior is controlled by anxiety arousal is also disputed by several lines of evidence. Autonomic arousal, which constitutes the principal index of anxiety,-is not necessary for defensive learning. Because autonomic reactions take much longer to activate than do avoidance responses, the latter cannot be caused by the former. Studies in which autonomic and avoidance responses are measured concurrently indicate that these two modes of activity may be partially correlated in the acquisition phase but are not causally related (Black, 1965). Avoidance behavior, for example, can persist long after autonomic reactions to threats have been extinguished. Surgical removal of autonomic feedback capability in animals has little effect on the acquisition of avoidance responses (Rescorla \& Solomon, 1967). Maintenance of avoidance behavior is even less dependent on autonomic feedback. Once defensive behavior has been learned, depriving animals of autonomic feed- 
back does not hasten the rate at which such activities are extinguished.

Research casts doubt on the postulated reinforcement sources, as well as the activating sources, of defensive behavior. In the dual-process theory, the anxiety reduction occasioned by escape from the feared stimulus presumably reinforces the defensive behavior. The evidence, however, reveals that whether or not defensive behavior removes the feared stimulus has variable effects on the maintenance of the behavior (Bolles, 1972a). Moreover, defensive behavior can be acquired and maintained by its success in diminishing the frequency of aversive stimulation, even though there are no feared stimuli to arouse anxiety and to provide the source of decremental reinforcement (Herrnstein, 1969). The substantial negative evidence concerning an anxiety mediational mechanism in avoidance behavior suggests that the effects of desensitization treatment must result from some other mechanism of operation.

Social learning theory regards anxiety and defensive behavior as coeffects rather than as causally linked (Bandura, 1977). Aversive experiences, either of a personal or vicarious sort, create expectations of injurious effects that can activate both fear and defensive behavior. Being coeffects, there is no fixed relationship between autonomic arousal and actions. Until effective coping behaviors are achieved, perceived threats produce high emotional arousal and various defensive maneuvers. But after people become adept at self-protective behaviors, they perform them in potentially threatening situations without having to be frightened (Notterman et al., 1952). Should their habitual coping devices fail, they experience heightened arousal until new defensive learning reduces their vulnerability.

Perceived threats activate defensive behavior because of their predictive value rather than their aversive quality. That is, when formerly neutral stimuli are associated with painful experiences, it is not that the stimuli have become aversive but that individuals have learned to anticipate aversive consequences. It is people's knowledge of their environment, not the stimuli, that are changed by correlated experience. Stimuli having predictive significance signal the likelihood of painful consequences unless protective measures are taken. Defensive behavior, in turn, is maintained by its success in forestalling or reducing the occurrence of aversive events. Once established, self-protective behavior is difficult to eliminate even though the hazards no longer exist. This is because consistent avoidance prevents a person from learning that the real-life conditions have changed. Hence, the nonoccurrence of anticipated hazards reinforces the expectation that the defensive maneuvers forestalled them.

From the perspective of dual-process theory, thorough extinction of anxiety should eliminate avoidance behavior. In the desensitization treatment, however, anxiety reactions are typically extinguished to visualized representations of feared situations. One would expect some transfer loss of extinction effects from symbolic to real-life threats, as is indeed the case (Agras, 1967; Barlow et al., 1969). It is not uncommon for people to fear and avoid real-life situations to which they have been desensitized in imagery. Therefore, according to this view, thorough extinction of anxiety to visualized threats should produce substantial, though less than complete, reductions in defensive behavior. However, dual-process theory provides no basis for predicting either the level of behavior change or the variability in behavior displayed by subjects who have all been equally desensitized.

In the social learning analysis presented earlier, reducing physiological arousal improves performance by raising efficacy expectations rather than by eliminating a drive that instigates the defensive behavior. This information-based view of the mediating mechanism predicts that the higher and stronger the efficacy expectations instated by desensitization procedures, the greater are the reductions in defensive behavior. Because arousal is only one of several sources of efficacy information, and not necessarily the most dependable one, extinguishing anxiety 


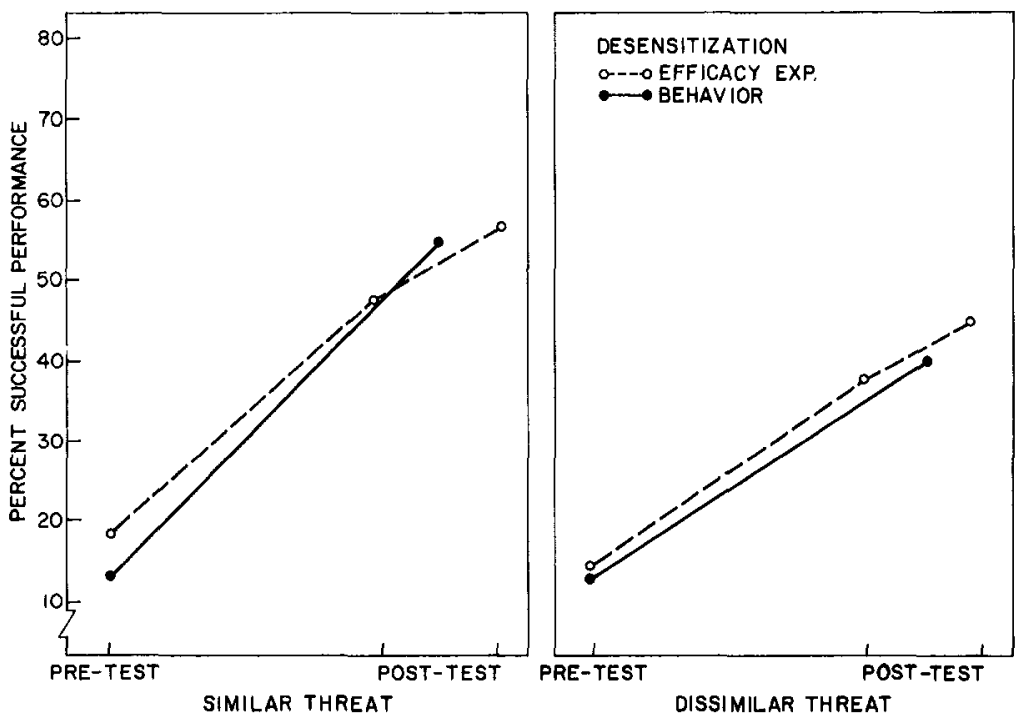

Figure 5. Level of efficacy expectations and approach behavior displayed by subjects toward different threats after their emotional reactions to symbolic representations of feared activities were eliminated through systematic desensitization. (Bandura \& Adams, in press.)

arousal is rarely a sufficient condition for eliminating defensive behavior.

To test the theory that desensitization changes behavior through its intervening effects on efficacy expectations, severe snake phobics were administered the standard desensitization treatment until their emotional reactions were completely extinguished to imaginal representations of the most aversive scenes (Bandura \& Adams, in press). The assessment procedures were identical to those used in the preceding experiment. Subjects' approach behavior was tested on the series of performance tasks before and after the desensitization treatment. The level, strength, and generality of their efficacy expectations were similarly measured before treatment, upon completion of treatment but prior to the posttest, and following the posttest.

The findings show that phobics whose anxiety reactions to visualized threats have been thoroughly extinguished emerge from the desensitization treatment with widely differing efficacy expectations. As depicted graphically in Figure 5, performance corresponds closely to level of self-efficacy. The higher the subjects' level of perceived self- efficacy at the end of treatment, the more approach behavior they subsequently performed in the posttest assessment $(r=.74)$.

Results of the microanalysis of congruence between self-efficacy at the end of treatment and performance on each of the tasks administered in the posttest are consistent with the findings obtained from enactive and vicarious treatment. Self-efficacy was an accurate predictor of subsequent performance on $85 \%$ for all the tasks, and $83 \%$ for the subset of tasks that subjects were unable to perform in the pretest assessment. Subjects successfully executed tasks within the range of their perceived self-efficacy produced by the desensitization treatment, whereas they failed at tasks they perceived to be beyond their capabilities.

\section{Microanalysis of Self-efficacy and Performance During the Process of Change}

The preceding series of experiments examined the predictive value of self-efficacy at the completion of different modes of treatment. A further study investigated the process of efficacy and behavioral change during the course of treatment itself. Participant model- 
ing was selected for this purpose because the amount of treatment can be well-regulated and it promotes rapid change.

As in the previous studies, adults whose lives were adversely affected by severe snake phobias were tested for their efficacy expectations and approach behavior using the microanalytic methodology described earlier. The various treatment activities were segmented into natural blocks of tasks of increasing difficulty and threat value. Items in the initial block included looking at a snake from progressively closer distances; intermediate blocks required subjects to touch and to hold the snake with gloved and bare hands for increasing intervals; the terminal block required them to tolerate the snake crawling about freely in their laps for an extended period. Subjects received the participant modeling treatment only for the block of items they failed in the hierarchy of assessment tasks. Treatment was continued until they could perform the activities in the failed block, whereupon they were tested for their efficacy expectations and approach responses on the succeeding tasks. Subjects who attained terminal performances received no further treatment. For those who achieved only partial improvement, the sequence of treatment on the failed block followed by assessments of self-efficacy and approach behavior on succeeding blocks was repeated until they achieved terminal performances.

Findings of the microanalysis lend further support to the postulated cognitive mechanism of change. Subjects who mastered the same intermediate performances during the course of treatment varied considerably in their behavioral attainments when tested on succeeding blocks of tasks. Past performance was therefore of limited value in predicting what subjects would be able to do when confronted with more threatening tasks. However, efficacy judgments proved to be good predictors of degree of behavioral change resulting from partial mastery experiences. Self-efficacy predicted subsequent performance as measured at different points in treatment in $92 \%$ of the total assessment tasks. This relationship holds even when the measure of congruence is based only on the subset of activities that subjects could not perform in pretest because they found them too threatening, and did not perform in treatment because the activities extended beyond the failed block. Expectations of personal effectiveness formed through partial mastery experiences during the course of treatment predicted, at a $84 \%$ level of accuracy, performance on highly threatening tasks that subjects had never done before.

\section{Concluding Remarks}

The present theoretical formulation orders variations in the level of behavioral changes produced by different modes of treatment; it accounts for behavioral variations displayed by individuals receiving the same type of treatment; and it predicts performance successes at the level of individual tasks during and after treatment. It is possible to generate alternative explanations for particular subsets of data, but the mechanism proposed in the present theory appears to account equally well for the different sets of findings. It might be argued, for example, that self-efficacy proved to be an accurate predictor of performance in the enactive mode of treatment because subjects were simply judging their future performance from their past behavior. However, an interpretation of this type has no explanatory value for the vicarious and emotive treatments, in which perceived selfefficacy was an equally accurate predictor of performance although subjects engaged in no overt behavior. Even in the enactive treatment, perceived self-efficacy proved to be a better predictor of behavior toward unfamiliar threats than did past performance. Moreover, self-efficacy derived from partial enactive mastery during the course of treatment predicted performance on stressful tasks that the individuals had never done before.

As an alternative explanation, one could invoke a superordinate mediator that controls both efficacy expectations and behavior. Although such a possibility is not inconceivable, the mediator would have to be an exceedingly complex one to account adequately for the diverse sets of relationships. To cite but a few examples, it would have to affect differentially efficacy expectations and be- 
havior resulting from maximal enactive mastery; somehow, it would have to produce different levels of self-efficacy from equivalent reductions in emotional arousal; and it would have to generate some variation in efficacy expectations from similar partial mastery experiences. The theory presented here posits a central processor of efficacy information. That is, people process, weigh, and integrate diverse sources of information concerning their capability, and they regulate their choice behavior and effort expenditure accordingly.

Evidence that people develop somewhat different efficacy expectations from similar enactive mastery and fear extinction warrants comment. One possible explanation for the variance is in terms of differential cognitive processing of efficacy information. To the extent that individuals differ in how they cognitively appraise their arousal decrements and behavioral attainments, their percepts of self-efficacy will vary to some degree. A second possibility concerns the multiple determination of self-efficacy. Because people have met with different types and amounts of efficacy-altering experiences, providing one new source of efficacy information would not be expected to affect everyone uniformly. Thus, for example, extinguishing arousal to threats will enhance self-efficacy, but more so in individuals whose past coping attempts have occasionally succeeded than in those who have consistently failed.

The research completed thus far has tested the predictive power of the conceptual scheme for efficacy expectations developed through enactive, vicarious, and emotive-based procedures. Additional tests of the generality of this approach need to be extended to efficacy expectations arising from verbal persuasion and from other types of treatments aimed at reducing emotional arousal.

Cognitive processing of efficacy information, which is an important component function in the proposed theory, is an especially relevant area for research. A number of factors were identified as influencing the cognitive appraisal of efficacy information conveyed by each of the major sources of selfefficacy. Previous research from a number of different perspectives demonstrating that some of these factors affect attitudinal and behavioral changes has suggestive value. But it is investigations that include assessment of the intervening self-efficacy link that can best provide validity for the present theory.

The operative process involved in the relationship between efficacy expectations and action also requires further investigation. It will be recalled that efficacy expectations are presumed to influence level of performance by enhancing intensity and persistence of effort. In the preceding experiments, the behavioral tasks were ordered in level of difficulty and subjects either persisted in their efforts until they completed all of the tasks or they quit at varying points along the way. The number of tasks successfully completed reflects degree of perseverance. As a further step toward elucidating the intervening process, it would be of interest to measure the intensity and duration of effort subjects exert in attempts to master arduous or insoluble tasks as a function of the level and strength of their efficacy expectations. Further research on the processes postulated in the present theoretical formulation should increase our understanding of the relationship between cognitive and behavioral change.

\section{References}

Agras, W. S. Transfer during systematic desensitization therapy. Behaviour Research and Therapy, 1967, 5, 193-199.

Averill, J. R. Personal control over aversive stimuli and its relationship to stress. Psychological Bulletin, 1973, 80, 286-303.

Bandura, A. Principles of behavior modification. New York: Holt, Rinehart \& Winston, 1969.

Bandura, A. (Ed.). Psychological modeling: Conflicting theories. Chicago: Aldine-Atherton, 1971.

Bandura, A. Effecting change through participant modeling. In J. D. Krumboltz \& C. E. Thoresen (Eds.), Counseling methods. New York: Holt, Rinehart \& Winston, 1976. (a)

Bandura, A. Self-reinforcement: Theoretical and methodological considerations. Behaviorism, 1976, 4, 135-155. (b)

Bandura, A. Social learning theory. Englewood Cliffs, N.J.: Prentice-Hall, 1977.

Bandura, A., \& Adams, N. E. Analysis of self-efficacy theory of behavioral change. Cognitive Therapy and Research, in press.

Bandura, A., Adams, N. E., \& Beyer, J. Cognitive 
processes mediating behavioral changes. Journal of Personality and Social Psychology, in press.

Bandura, A., \& Barab, P. G. Processes governing disinhibitory effects through symbolic modeling. Journal of Abnormal Psychology, 1973, 82, 1-9.

Bandura, A., Blanchard, E. B., \& Ritter, B. The relative efficacy of desensitization and modeling approaches for inducing behavioral, affective, and attitudinal changes. Journal of Personality and Social Psychology, 1969, 13, 173-199.

Bandura, A., Jeffery, R.'W., \& Gajdos, E. Generalizing change through participant modeling with self-directed mastery. Behaviour Research and Therapy, 1975, 13, 141-152.

Bandura, A., Jeffery, R. W., \& Wright, C. L. Efficacy of participant modeling as a function of response induction aids. Journal of Abnormal Psychology, 1974, 83, 56-64.

Bandura, A., \& Menlove, F. L. Factors determining vicarious extinction of avoidance behavior through symbolic modeling. Journal of Personality and Social Psychology, 1968, 8, 99-108.

Barlow, D. H., Leitenberg, H., Agras, W. S., \& Wincze, J. P. The transfer gap in systematic desensitization: An analogue study. Behaviour Re. search and Therapy, 1969, 7, 191-196.

Baron, A., Kaufman, A., \& Stauber, K. A. Effects of instructions and reinforcement-feedback on human operant behavior maintained by fixed-interval reinforcement. Journal of the Experimental Analysis of Behavior, 1969, 12, 701-712.

Baum, W. M. The correlation-based law of effect. Journal of the Experimental Analysis of Behavior, 1973, 20, 137-153.

Bem, D. J. Self-perception theory. In L. Berkowitz (Ed.), Advances in experimental social psychology (Vol, 6). New York: Academic Press, 1972.

Black, A. H. Cardiac conditioning in curarized dogs: The relationship between heart rate and skeletal behaviour. In W. F. Prokasy (Ed.), Classical conditioning: $A$ symposium. New York: Appleton-Century-Crofts, 1965.

Blanchard, E. B. The generalization of vicarious extinction effects. Behaviour Research and Therapy, 1970, 7, 323-330. (a)

Blanchard, E. B. Relative contributions of modeling, informational influences, and physical contact in extinction of phobic behavior. Journal of Abnormal Psychology, 1970, 76, 55-61. (b)

Bolles, R. C. The avoidance learning problem. In G. Bower (Ed.), The psychology of learning and motivation (Vol. 6). New York: Academic Press, 1972. (a)

Bolles, R. C. Reinforcement, expectancy, and learning. Psychological Review, 1972, 79, 394-409. (b)

Borkovec, T. D. The role of expectancy and physiological feedback in fear research: A review with special reference to subject characteristics. $B e$ havior Therapy, 1973, 4, 491-505.

Bootzin, R. R., Herman, C. P., \& Nicassio, P. The power of suggestion: Another examination of misattribution and insomnia. Journal of Personality and Social Psychology, 1976, 34, 673-679.
Calvert-Boyanowsky, J., \& Leventhal, H. The role of information in attenuating behavioral responses to stress: A reinterpretation of the misattribution phenomenon. Journal of Personality and Social Psychology, 1975, 32, 214-221.

Davison, G. C., \& Wilson, G. T. Processes of fearreduction in systematic desensitization: Cognitive and social reinforcement factors in humans. $B e$ havior Therapy, 1973, 4, 1-21.

Dawson, M. E., \& Furedy, J. J. The role of awareness in human differential autonomic classical conditioning: The necessary-gate hypothesis. Psychophysiology, 1976, 13, 50-53.

Dulany, D. E. Awareness, rules, and propositional control: A confrontation with $\mathbf{S}-\mathbf{R}$ behavior theory. In T. R. Dixon \& D. L. Horton (Eds.), Verbal behavior and general behavior theory. Englewood Cliffs, N.J.: Prentice-Hall, 1968.

Emmelkamp, P. M. G., \& Wessels, H. Flooding in imagination vs. flooding in vivo: A comparison with agoraphobics. Behaviour Research and Therapy, 1975, 13, 7-15.

Estes, W. K. Reinforcement in human behavior. American Scientist, 1972, 60, 723-729.

Flanders, J. P. A review of research on imitative behavior. Psychological Bulletin, 1968, 69, 316-337.

Gaupp, L. A., Stern, R. M., \& Galbraith, G. G. False heart-rate feedback and reciprocal inhibition by aversion relief in the treatment of snake avoidance behavior Behavior Therapy, 1972, 3, $7-20$.

Grings, W. W. The role of consciousness and cognition in autonomic behavior change. In F. J. McGuigan \& R. A. Schoonover (Eds.), The psychophysiology of thinking. New York: Academic Press, 1973.

Heneman, H. G., III, \& Schwab, D. P. Evaluation of research on expectancy theory predictions of employee performance Psychological Bulletin, $1972,78,1-9$.

Herrnstein, R. J. Method and theory in the study of avoidance. Psychological Review, 1969, 76, 4969.

Howlett, S. C., \& Nawas, M. M. Exposure to aversive imagery and suggestion in systematic desensitization. In R. D. Rubin, A. A. Lazarus, H. Fensterheim, \& C M. Franks (Eds.), Advances in behavior therapy. New York: Academic Press, 1971.

Hunt, J. McV, Cole, M. W., \& Reis, E. E. S. Situational cues distinguishing anger, fear, and sorrow. American Journal of Psychology, 1958, 71, 136-151.

Irwin, F. W. Intentional behavior and motivation: A cognitive view. Philadelphia: Lippincott, 1971.

Kaufman, A., Baron, A., \& Kopp, E. Some effects of instructions on human operant behavior. Psychonomic Monograph Supplements, 1966, 1, 243250 .

Kazdin, A. E. Covert modeling and the reduction of avoidance behavior. Journal of Abnormal Psychology, 1973, 81, 87-95.

Kazdin, A. E. Comparative effects of some varia- 
tions of covert modeling. Journal of Behavior Therapy and Experimental Psychiatry, 1974, 5, 225-232. (a)

Kazdin, A. E. Covert modeling, model similarity, and reduction of avoidance behavior. Behavior Therapy, 1974, 5, 325-340. (b)

Kazdin, A. E. Effects of covert modeling and reinforcement on assertive behavior. Journal of Abnormal Psychology, 1974, 83, 240-252. (c)

Kazdin, A. E. Covert modeling, imagery assessment, and assentive behavior. Journal of Consulting and Clinical Psychology, 1975, 43, 716-724.

Kazdin, A. E. Effects of covert modeling, multiple models, and model reinforcement on assertive behavior. Behavior Therapy, 1976, 7, 211-222.

Kellogg, R., \& Baron, R. S. Attribution theory, insomnia, and the reverse placebo effect: A reversal of Storms and Nisbett's findings, Journal of Personality and Social Psychology, 1975, 32, 231-236.

Kent, R. N., Wilson, G. T., \& Nelson, R. Effects of false heart-rate feedback on avoidance behavior: An investigation of "cognitive desensitization." Behavior Therapy, 1972, 3, 1-6.

Kopel, S., \& Arkowitz, H. The role of attribution and self-perception in behavior change: Implications for behavior therapy. Genetic Psychology Monographs, 1975, 92, 175-212.

Lewis, S. A comparison of behavior therapy techniques in the reduction of fearful avoidance behavior. Behavior Therapy, 1974, 5, 648-655.

Lick, J., \& Bootzin, R. Expectancy factors in the treatment of fear: Methodological and theoretical issues. Psychological Bulletin, 1975, 82, 917-931.

Litvak, S. B. A comparison of two brief group behavior therapy techniques on the reduction of avoidance behavior. The Psychological Record, 1969, 19, 329-334.

LoPiccolo, J. Effective components of systematic desensitization (Doctoral dissertation, Yale University, 1969). Dissertation Abstracts International, 1970, 31, 1543B. (University Microfilms No. 7016300)

Maier, S. F., \& Seligman, M. E. Learned helplessness: Theory and evidence. Journal of Experimental Psychology, 1976, 105, 3-46.

Mandler, G. Mind and emotion. New York: Wiley, 1975.

McGlynn, F. D., \& Mapp, R. H. Systematic desensitization of snake-avoidance following three types of suggestion. Behaviour Research and Therapy, 1970, 8, 197-201.

McGlynn, F. D., Mealiea, W. L., \& Nawas, M. M. Systematic desensitization of snake-avoidance under two conditions of suggestion. Psychological Reports, 1969, 25, 220-222.

McGlynn, F. D., Reynolds, E. J., \& Linder, L. H. Systematic desensitization with pre-treatment and intra-treatment therapeutic instructions. Behaviour Research and Therapy, 1971, 9, 57-63.

Meichenbaum, D. H. Examination of model characteristics in reducing avoidance behavior. Journal of Personality and Social Psychology, 1971, 17, 298-307.

Moore, N. Behaviour therapy in bronchial asthma: A controlled study. Journal of Psychosomatic Research, 1965, 9, 257-276.

Nisbett, R. E., \& Schachter, S. Cognitive manipulation of pain. Journal of Experimental Social Psychology, 1966, 2, 227-236.

Notterman, J. M., Schoenfeld, W. N., \& Bersh, P. J. A comparison of three extinction procedures following heart rate conditioning. Journal of $A b$ normal and Social Psychology, 1952, 47, 674-677.

Paul, G. L. Insight vs. desensitization in psychotherapy. Stanford, Calif.: Stanford University Press, 1966.

Rabavilas, A. D., Boulougouris, J. C., \& Stefanis, C. Duration of flooding sessions in the treatment of obsessive-compulsive patients. Behaviour $R e$ search and Therapy, 1976, 14, 349-355.

Rescorla, R. A, \& Solomon, R. L. Two-process learning theory: Relationships between Pavlovian conditioning and instrumental learning. Psychological Review, 1967, 74, 151-182.

Ritter, B. The use of contact desensitization, demonstration-plus-participation, and demonstration alone in the treatment of acrophobia. Behaviour Research and Therapy, 1969, 7, 157-164.

Röper, G., Rachman, S., \& Marks, I. Passive and participant modelling in exposure treatment of obsessive-compulsive neurotics. Behaviour Research and Therapy, 1975, 13, 271-279.

Rosen, G. M., Rosen, E., \& Reid, J. B. Cognitive desensitization and avoidance behavior: A reevaluation. Journal of Abnormal Psychology, 1972, 80, 176-182.

Ross, L., Rodin, J., \& Zimbardo, P. T. Toward an attribution therapy: The reduction of fear through induced cognitive-emotional misattribution. Journal of Personality and Social Psychology, 1969, 12, 279-288.

Rotter, J. B. Generalized expectancies for internal versus external control of reinforcement. Psychological Monographs, 1966, 80(1, Whole No. 609).

Sarason, I, G. Anxiety and self-preoccupation. In I. G. Sarason \& C. D. Spielberger (Eds.), Stress and anxiety (Vol. 2). Washington, D.C.: Hemisphere, 1976.

Schachter, S. The interaction of cognitive and physiological determinants of emotional state. In L. Berkowitz (Ed.), Advances in experimental social psychology. New York: Academic Press, 1964.

Schachter, S., \& Singer, J. E. Cognitive, social, and physiological determinants of emotional state. Psychological Review, 1962, 69, 379-399.

Sherman, A. R., Real-life exposure as a primary therapeutic factor in the desensitization treatment of fear. Journal of Abnormal Psychology, $1972,79,19-28$.

Singerman, K. J., Borkovec, T. D., \& Baron, R. S. Failure of a "misattribution therapy" manipula- 
tion with a clinically relevant target behavior. Behavior Therapy, 1976, 7, 306-313.

Stern, R., \& Marks, I. Brief and prolonged flooding: A comparison in agoraphobic patients. Archives of General Psychiatry, 1973, 28, 270-276.

Strahley, D. F. Systematic desensitization and counterphobic treatment of an irrational fear of snakes (Doctoral dissertation, University of Tennessee, 1965). Dissertation Abstracts, 1966, 27, 973B. (University Microfilms No, 66-5366)

Sushinsky, L. W., \& Bootzin, R. R. Cognitive desensitization as a model of systematic desensitization. Behaviour Research and Therapy, 1970, 8, 29-33.

Szpiler, J. A., \& Epstein, S. Availability of an avoidance response as related to autonomic arousal. Journal of Abnormal Psychology, 1976, 85, 73-82.

Thase, M. E., \& Moss, M. K. The relative efficacy of covert modeling procedures and guided participant modeling in the reduction of avoidance behavior. Journal of Behavior Therapy and Experimental Psychiatry, 1976, 7, 7-12.

Valins, S., \& Nisbett, R. E. Attribution processes in the development and treatment of emotional disorders. Morristown, N.J.: General Learning Press, 1971.

Valins, S., \& Ray, A. Effects of cognitive desensitization on avoidance behaviour. Journal of Personality and Social Psychology, 1967, 7, 345350.

Watson, J. P., Mullett, G. E., \& Pillay, H. The effects of prolonged exposure to phobic situations upon agoraphobic patients treated in groups. $B e-$ haviour Research and Therapy, 1973, 11, 531545.

Weiner, B. Theories of motivation. Chicago: Markham, 1972.

White, R. W. Motivation reconsidered: The concept of competence. Psychological Review, 1959, $66,297-333$.

Wilson, G. T., \& Davison, G. C. Processes of fear reduction in systematic desensitization: Animal studies. Psychological Bulletin, 1971, 76, 1-14.

Wolpe, J. The practice of behavior therapy. New York: Pergamon Press, 1974.

Received June 30, 1976 